\title{
Summary of recommendations on percutaneous coronary intervention for the reperfusion of acute ST elevation myocardial infarction
}

\author{
G Montalescot, H R Andersen, D Antoniucci, A Betriu, M J de Boer, L Grip, F J Neumann, \\ M T Rothman
}

S ince primary percutaneous coronary intervention (PCI) is the mainstay of reperfusion in acute myocardial infarction (AMI), and because AMI represents the most urgent situation for PCI, recommendations based on scientific evidence and expert experience would be useful for centres practising primary PCI or those looking to set up a primary PCI programme. With this in mind, a group of eight European interventional cardiologists (all based at high volume centres) formed an expert consensus to provide recommendations on this subject.

The recommendations are intended for specialists who possess the necessary knowledge, experience, and skills to perform PCI, and who work in environments with appropriate resources and facilities.

\section{RECOMMENDATIONS FOR PCI IN AMI}

When performed by experienced operators, we strongly recommend PCI as the reperfusion strategy of choice for patients with AMI. When thrombolysis is contraindicated or has failed, or when patients are in cardiogenic shock, rapid transfer to a secondary unit should be ensured. Studies have shown that, where facilities are available, most AMI patients are candidates for PCI, ${ }^{1}$ and that PCI is effective in reestablishing coronary artery perfusion and in providing a good outcome in both the short and long term. ${ }^{2}$

We strongly recommend that PCI for AMI is performed swiftly, with a door-to-balloon time of $<2$ hours. The benefit of reperfusion with primary PCI is maximal within two hours of symptom onset, but appears to be present in a time window of 12 hours between onset of chest pain and PCI. ${ }^{2}$ Mortality is also linked to door-to-balloon time, with a significant increase in mortality when times exceed two hours. ${ }^{3}$ We would therefore strongly recommend the transfer of AMI patients to cardiac catheterisation laboratories if the expected time to arrival is likely to be $\leqslant 2$ hours. If the time to catheterisation is likely to exceed three hours, thrombolysis should be regarded as a valid option. If a patient undergoing thrombolytic therapy does not have signs of reperfusion 90 minutes after starting the therapy, transfer for rescue PCI should be considered. A number of studies and a recent meta-analysis have demonstrated the feasibility and benefit of transferring patients to units with cardiac catheterisation facilities. ${ }^{4}$

PCI should ideally be performed in high volume centres (> 33 primary PCI procedures per year) with fully equipped interventional laboratories and experienced support staff. ${ }^{1}$

Considering the high risks associated with many of these urgent procedures, we recommend that a complete, well trained team of nurses and, wherever possible, two physicians should be present in the catheterisation laboratory throughout the procedure (one senior interventionalist for the PCI procedure and one physician to monitor the patients' haemodynamic, respiratory and, if necessary, anaesthetic state). ${ }^{1}$ Many centres use only one physician; a single physician, however, cannot manage the most difficult cases involving cardiac arrest, cardiogenic shock, and a need for intubation with complete safety. Good outcomes can be achieved in hospitals without cardiac surgery support given successful completion of a PCI training programme and appropriate selection of cases. ${ }^{5}$ A broad range of catheters, guidewires, stents, and supportive devices such as intraaortic balloon pumps (IABP) should also be available in these hospitals.

There is clear evidence and guidelines stating that PCI for AMI should be performed in high volume centres (400 PCI cases per year in total). ${ }^{1}$ However, the C-PORT study showed that after selection of cases, patients who are out of range of high volume centres could be successfully treated in low volume centres with well trained teams. ${ }^{5}$

We strongly recommend the use of stents for AMI and the use of direct stenting whenever possible. IABPs should be available and their use is strongly recommended in patients with AMI complicated by cardiogenic shock. Radial access is a good alternative to the femoral approach but only in centres already routinely using this approach for elective cases. We do not recommend the systematic use of closure devices in AMI patients. Although promising, the use of thrombectomy and distal protection devices carry the risk of dislodging a thrombus during delivery.

Our recommendations for the use of pharmacological treatments are outlined below. The use of aspirin in reducing ischaemic complications after coronary angioplasty is widely accepted $^{1}$ and therefore aspirin should be given as early as possible, with a recommended starting dose > $160 \mathrm{mg}$; intravenous administration is preferable.

Whenever possible, a loading dose of 300-600 mg clopidogrel is recommended before intervention and a daily dose of at least $75 \mathrm{mg}$ clopidogrel for at least one month postintervention.

To date, abciximab is the only glycoprotein IIb/IIIa inhibitor proven to be clinically effective in PCI for AMI. ${ }^{6-10}$ Trials, including RAPPORT, ISAR-2, ADMIRAL, CADILLAC, and $\mathrm{ACE}$, have demonstrated the efficacy of abciximab during PCI for AMI. All five trials testing abciximab in primary angioplasty showed significant reductions in ischaemic events at 30 days. Therefore, immediate administration of abciximab on first presentation is recommended for AMI patients scheduled for primary PCI.

We recommend the administration of heparin at a dose adjusted to weight and/or activated clotting time (ACT). We

Abbreviations: $A C T$, activated clotting time; $A M I$, acute myocardial infarction; IABP, intra-aortic balloon pump; $\mathrm{PCl}$, percutaneous coronary intervention; UFH, unfractionated heparin. 
Table 1 Recommendations for specific cases and post- $\mathrm{PCl}$

\begin{tabular}{|c|c|}
\hline Case & Recommendation \\
\hline Facilitated PCI & $\begin{array}{l}\text { - Facilitated PCI with pharmacological treatment helps establish early reperfusion } \\
\text { before catheterisation } \\
\text { - Facilitation with abciximab is the only recommendation based on published } \\
\text { positive studies }\end{array}$ \\
\hline $\begin{array}{l}\mathrm{PCl} \text { in coronary artery } \\
\text { bypass grafts }\end{array}$ & $\begin{array}{l}\text { - When dilating a saphenous vein graft, the use of distal protection devices or } \\
\text { thrombectomy devices may help prevent post-procedural events, such as no } \\
\text { reflow and cardiogenic shock } \\
\text { - Considering the limited options available, PCl is a valid therapeutic strategy in } \\
\text { these patients }\end{array}$ \\
\hline $\begin{array}{l}\text { Culprit vessel versus all } \\
\text { vessel intervention }\end{array}$ & $\begin{array}{l}\text { - Given the lack of conclusive supporting evidence, the consensus among experts } \\
\text { is that "culprit only" intervention should be the recommended strategy. However, } \\
\text { all accessible vessels should be treated in patients with shock }\end{array}$ \\
\hline Cardiogenic shock & $\begin{array}{l}\text { - We recommend careful assessment of the risk of developing cardiogenic shock } \\
\text { in each patient to ensure early diagnosis and to allow rapid transfer and } \\
\text { adequate intervention }\end{array}$ \\
\hline $\begin{array}{l}\text { No reflow and myocardial } \\
\text { blush below grade } 3\end{array}$ & $\begin{array}{l}\text { - Glyceryl trinitrate, verapamil, papaverine, nitroprusside, and adenosine are not } \\
\text { recommended at this time. Optimal treatment for no reflow remains } \\
\text { undetermined }\end{array}$ \\
\hline Elderly patients & $\begin{array}{l}\text { - Elderly patients are generally good candidates for angioplasty (and less so for } \\
\text { thrombolysis) }\end{array}$ \\
\hline Post-PCl & $\begin{array}{l}\text { - Early discharge (day 3) after optimal PCI for uncomplicated AMI in low risk } \\
\text { patients is recommended. }\end{array}$ \\
\hline Length of hospital stay & $\begin{array}{l}\text { - Early discharge is not recommended in high risk patients or following any } \\
\text { complication or unsatisfactory procedure. }\end{array}$ \\
\hline
\end{tabular}

recommend $70 \mathrm{U}$ of unfractionated heparin (UFH) per kilogram in patients undergoing PCI with adjuvant glycoprotein IIb/IIIa inhibitors. Higher doses of UFH used together with glycoprotein IIb/IIIa inhibitors are associated with a risk of over-anticoagulation. Substitution of low molecular weight heparin for UFH appears promising but firm recommendations cannot be given at this time.

The American College of Cardiology recommends that patients not receiving glycoprotein IIb/IIIa inhibitors should be given sufficient UFH during coronary angioplasty to achieve an ACT of 250-300 s and 300-350 s. The UFH bolus should be reduced when glycoprotein IIb/IIIa inhibitors are given to achieve a target ACT of 200 s. ${ }^{1}$

\section{CONCLUSION}

This is the first paper to draw together a full range of recommendations for PCI in AMI including timing, adjunctive pharmacological therapies and length of hospital stay post-PCI. More detailed analysis of the evidence supporting these recommendations can be found in the electronic version of this paper.

\section{ACKNOWLEDGEMENTS}

This European Expert Consensus was supported by an unrestricted educational grant from Eli Lilly and Company.

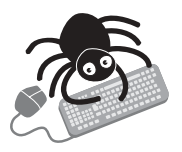

To view to the full recommendations, go to the Heart website-http://www.heartinl.com/cgi/content/full/ 90/6/e37

\section{Authors' affiliations}

G Montalescot, Centre Hospitalier Universitaire Pitié-Salpétrière, Paris, France

H R Andersen, Skejby University Hospital, Aarhus, Denmark

D Antoniucci, Ospedale Careggi, Firenze, Italy

A Betriu, Hospital Clinico, Barcelona, Spain

M J de Boer, Isala Klinieken, Zwolle, The Netherlands

L Grip, Sahlgrenska University Hospital, Göteborg, Sweden
F J Neumann, Herzzentrum Bad Krozingen, Bad Krozingen, Germany M T Rothman, The London Chest Hospital, London, UK

Correspondence to: $\operatorname{Dr} G$ Montalescot, Institut de Cardiologie, Bureau 2-236, Centre Hospitalier Universitaire Pitié-Salpétrière, $47 \mathrm{BI}$ de l'Hôpital, 75013 Paris, France; gilles.montalescot@psl.ap-hop-paris.fr

Accepted 5 December 2003

\section{REFERENCES}

1 Smith SC Jr, Dove JT, Jacobs AK, et al. American College of Cardiology; American Heart Association task force on practice guidelines. Committee to revise the 1993 guidelines for percutaneous transluminal coronary angioplasty. ACC/AHA guidelines of percutaneous coronary interventions (revision of the 1993 PTCA guidelines): executive summary. A report of the American College of Cardiology/American Heart Association task force on practice guidelines. J Am Coll Cardiol 2001;37:2215-39.

2 Brodie BR, Grines CL, Ivanhoe R, et al. Six-month clinical and angiographic follow-up after direct angioplasty for AMl: final results from the primary angioplasty registry. Circulation 1994;90:156-62.

3 Cannon CP, Gibson CM, Lambrew CT, et al. Relationship of symptom-onsetto-balloon time and door-to-balloon time with mortality in patients undergoing angioplasty for acute myocardial infarction. JAMA 2000;283:2941-7.

4 Dalby M, Bouzamondo A, Lechat PH, et al. Transfer for primary angioplasty versus thrombolysis in acute myocardial infarction. A meta-analysis. Circulation 2003:108:1809-14.

5 Aversano T, Aversano LT, Passamani E, et al for the Atlantic Cardiovascular Patient Outcomes Research Team (C-PORT). Thrombolytic therapy vs primary percutaneous coronary intervention for myocardial infarction in patients presenting to hospitals without on-site cardiac surgery: a randomized controlled trial. JAMA 2002;287:1943-51.

6 Stone GW, Grines CL, Cox DA, et al. Comparison of angioplasty with stenting, with or without abciximab, in acute myocardial infarction. N Engl J Med 2002;346:957-66.

7 Brener SJ, Barr LA, Burchenal JE, et al. Randomized, placebo-controlled trial of platelet glycoprotein Ilb/llla blockade with primary angioplasty for acute myocardial infarction. ReoPro and primary PTCA organization and randomized trial (RAPPORT) investigators. Circulation 1998;98:734-41.

8 Neumann FJ, Kastrati A, Schmitt C, et al. Effect of glycoprotein Illb/llla receptor blockade with abciximab on clinical and angiographic restenosis rate after the placement of coronary stents following acute myocardial infarction. J Am Coll Cardiol 2000;35:915-21.

9 Montalescot G, Barragan P, Wittenberg O, et al. Platelet glycoprotein Ilb/Illa inhibition with coronary stenting for acute myocardial infarction. N Engl J Med 2001;344:1895-903.

10 Antoniucci D. The ACE trial - a prospective multicenter study of carbon coated stenting in AMI with and without abciximab. Transcatheter Cardiovascular Therapeutics 2002, 24-28 September 2002, Washington, DC, USA. 